Article

\title{
Comparison of the Evaporation and Condensation Heat Transfer Coefficients on the External Surface of Tubes in the Annulus of a Tube-in-Tube Heat Exchanger
}

\author{
Weiyu Tang ${ }^{1}$, David John Kukulka ${ }^{2, *}$, , Wei Li ${ }^{1}$ and Rick Smith ${ }^{3}$ \\ 1 Department of Energy Engineering, Zhejiang University, Hangzhou 310027, China; \\ tangweiyu@zju.edu.cn (W.T.); weili96@zju.edu.cn (W.L.) \\ 2 Department of Engineering Technology, State University of New York College at Buffalo, \\ New York, NY 14222, USA \\ 3 Vipertex Division, Rigidized Metals Corporation, Buffalo, New York, NY 14203, USA; \\ ricksmith@rigidized.com \\ * Correspondence: kukulkdj@buffalostate.edu; Tel.: +1-716-8784418
}

Received: 22 January 2020; Accepted: 17 February 2020; Published: 20 February 2020

\begin{abstract}
An experimental study was carried out to explore the heat transfer characteristics on the outside of smooth and enhanced tubes, during evaporation and condensation of R134A in the annulus of a tube-in-tube heat exchanger. The three-dimensional enhanced surface tube consisted of primary enhancement patterns and secondary patterns; results were compared to the performance of an equivalent smooth tube. The equivalent external diameter of the inside horizontal copper tubes used in this study was $19.05 \mathrm{~mm}$, while the outer tube varied in size, allowing a comparison of heat transfer for different annulus dimensions. Tests were conducted with a fixed inlet/outlet vapor quality and a constant saturation temperature for varied mass velocities in the range of 30 to $100 \mathrm{~kg} /\left(\mathrm{m}^{2} \cdot \mathrm{s}\right)$. For condensation, the ratio of heat transfer coefficient enhancement (enhanced tube/ smooth tube) was up to 1.78; this can be attributed to the turbulence increase, as well as liquid film re-distribution, produced from the dimples. Furthermore, the condensation heat transfer coefficient increased rapidly with increasing mass flux. For flow boiling in the annulus between the 1EHT tube and outer tube, the heat transfer coefficient during boiling was 11-36\% higher when compared to the smooth tube at $x_{\text {ave }}=0.35$, while the performance of the 1EHT tube was not as good as the smooth tube at $x_{\text {ave }}=0.5$. The heat transfer deterioration can be explained by decreased effective nucleate flow boiling heat transfer area and the flow pattern transition between a slug/wavy-stratified flow to wavy-stratified flow.
\end{abstract}

Keywords: evaporation; condensation; surface-enhanced tube; heat transfer coefficient

\section{Introduction}

The application of heat transfer enhancement technologies provides the potential to minimize cost, produce smaller units, and increase the reliability of heat exchangers. Enhanced tubes with passive enhancement can enhance the thermal performance while producing a small increase (when compared to a smooth tube) to pressure drop for most conditions. Therefore, widely used enhancement structures (such as micro-fin, herringbone, corrugated tubes, etc.) draw considerable attention in various industrial applications (i.e., air conditioning and refrigeration applications). According to Webb and Kim [1], three-dimensional enhanced tubes are good choices for heat transfer argumentation; three-dimensional enhanced tubes are considered here. Enhancement in these tubes is achieved 
by (i) increasing turbulence and surface area, (ii) producing fluid mixing and secondary flows, and (iii) interrupting boundary layers. Additionally, when compared to traditional two-dimensional enhancement techniques, the enhanced three-dimensional tubes provide better condensate drainage effects, and an increase in nucleate site densities can also be achieved using the unique characteristic structures that make up the enhancements (i.e., dimples, grooves, etc.).

Since these three-dimensional tubes are novel, only a few investigations were carried out into various condensation and evaporation heat transfer characteristics. Additional experimental, numerical, and optimization studies need to be performed in order to better understand the thermal potential of these three-dimensional enhanced tubes. Several previous investigations were conducted into the heat transfer performance of similar dimpled tubes. Wang et al. [2] experimentally studied the heat transfer and flow properties of a dimpled tube. The results showed that the Nusselt number was enhanced (when higher compared to the equivalent smooth tube) by $26.9-75 \%$ (for ellipsoidal dimpled tubes) and 32.9-92\% (spherical dimpled tubes). Ellipsoidal dimples on the inner surface can lower the laminar-to-turbulent transitional Reynolds number to a value less than 1000. Li et al. conducted numerical works [3] and geometrical optimizations [4] on the dimpled tubes, and they concluded that three-dimensional surfaces enhanced by dimples can significantly promote the thermal performance of heat exchangers; furthermore, the shape, depth, and arrangement of dimples significantly influence the thermal performance. Vicente et al. [5] investigated the heat transfer and pressure drop for low Reynolds flow in dimpled tubes. Similar experimental works were also reported by Kukulka et al. [6] to investigate the thermal performance of three-dimensional surfaces during single-phase flows. An overall parametric study and optimization was carried out recently by Lei et al. [7] based on a response surface methodology and desirability approach, while a combination of $\mathrm{CuO} /$ water nanofluid and dimpled tubes was investigated by Suresh et al. [8]. Therefore, additional optimization studies need to be performed in order to maximize the heat transfer efficiency. When considering two-phase flow application, limited previous investigations were found for the individual enhancement structures. Guo et al. [9] performed an experimental study that compared the convective heat transfer coefficient for a herringbone tube and a three-dimensional enhanced surface tube during condensation and evaporation of R22, R32, and R410A; they found that the herringbone tube provided a heat transfer coefficient increase of $200-300 \%$ when compared to a smooth tube during condensation; the heat transfer coefficient of the 1EHT (enhanced three-dimensional surface) tube was 1.3-1.95 times larger than that of the smooth tube. In addition, the 1EHT tube provided the best heat transfer performance during evaporation for the three working fluids. Li et al. [10] conducted experimental investigations to explore tube-side condensation and evaporation characteristics of two different 2EHT (a differently structured three-dimensional surface) enhanced tubes. Although negligible area enhancements were provided by these two enhanced tubes, the heat transfer coefficient ratio (when compared to an equivalent plain tube) was in the range of 1.1-1.43. Aroonerat and Wongwises conducted a series of experiments that were performed in order to determine the thermal performance of dimpled tubes [11], and the effect of dimple depths [12], helical angle, and dimple pitches [13] on the condensation heat transfer coefficient and pressure drop of R134a flowing in dimpled tubes. The results showed that the dimpled tube with the largest depth provided the highest heat transfer coefficient, as well as the largest pressure drop penalty (an unexpected pressure drop increase up to $892 \%$ higher than that of the smooth tube was reported). Sarmadian et al. [14] measured and analyzed the condensation heat transfer coefficient and frictional pressure drop of R600a in a helically dimpled tube. Their experimental results indicated that the heat transfer coefficients of the dimpled tube were 1.2-2 times higher than those found in an equivalent smooth tube with a pressure drop penalty ranging from $58 \%$ to $195 \%$ (when compared to smooth tubes). Their visualization showed that the dimples could accelerate the transition between annular and stratified flows. Shafaee et al. [15] performed a saturated flow boiling experiment and reported that the heat transfer performance was substantially improved because of the enhancement design. Additional enhancement structure design analyses were investigated by Ayub et al. [16], and their results show that, under similar operating conditions, the enhanced tube 
with a rod insert provided a three-fold higher heat transfer coefficient than the plain tube; additionally, the corresponding pressure drop penalty was even lower for low mass fluxes.

Several experimental investigations were conducted for two-phase heat transfer performance of annular (tube in tube) flows to evaluate the enhancement characteristics of two-sided, three-dimensional, dimple tubes. Li et al. [17] performed an experimental investigation on the shell-side flow condensation of R410A on horizontal tubes, at mass fluxes values in the range from $5-50 \mathrm{~kg} /\left(\mathrm{m}^{2} \cdot \mathrm{s}\right)$. Their results indicated that the smooth tube exhibited superior thermal performance over other enhanced tubes (herringbone and EHT tubes); this strange trend might be attributed to the liquid inundation at the lower portion in the annular, which results from surface tension effects. Tang and Li [18] carried out an experimental study on two horizontal enhanced tubes, as well as the enhanced surfaces that were made up of dimples, protrusions, and grooves. Mass flux and vapor qualities were varied in order to explore the possible mechanisms of the enhanced surfaces; results showed that the proposed enhanced tubes seemed to show a worse thermal performance than the smooth tube for $G<150 \mathrm{~kg} /\left(\mathrm{m}^{2} \cdot \mathrm{s}\right)$, while one of the enhanced tubes provided an enhanced heat transfer coefficient ratio in the range from 1.03-1.14 for $G=200 \mathrm{~kg} /\left(\mathrm{m}^{2} \cdot \mathrm{s}\right)$. All EHT tubes employed by Tang and Li [18] and Li et al. [17] had the same outer diameter of $12.7 \mathrm{~mm}$; future investigations should determine the effect of tube diameter on the heat transfer performance.

In this study, the three-dimensional enhanced (1EHT) tube and an equivalent plain tube with the same outer diameter of $19.05 \mathrm{~mm}$ were employed for shell-side condensation and evaporation heat transfer performance evaluation. Unlike traditional enhanced tubes such as micro-fin tubes, herringbone tubes, and typical dimpled tubes (as discussed in Aroonerat and Wongwises [19]), the 1EHT tube has a composite enhancement structure, which is made up of helically arranged dimples and petal arrays. The special surface structure of the 1EHT tube is shown in Figure 1. Dorao and Fernandino [20] suggested that the improvement in enhanced surfaces is connected to the improvement observed in the single-phase flow. The same article indicated that the delta-T-dependent region is related to improved mixing at the wall. Given this theory, the primary deep dimples were designed to increase fluid turbulence, enhance fluid mixing, and produce secondary flows, while a roughness was produced from the staggered petal arrays of shallow dimples that were designed for boundary layer interruption and nucleate site argumentation. As shown in Figure 1, the primary dimples of the $1 \mathrm{EHT}$ tube had a height of $1.71 \mathrm{~mm}$ and a typical projected diameter of $4.4 \mathrm{~mm}$. In addition, they were helically arranged on the external surface of tubes, with a pitch of $9.86 \mathrm{~mm}$ and a helical angle of $60^{\circ}$, and with an enhanced surface area ratio of 1.20 (internal surface area of the enhanced tube compared to that of the smooth tube). Detailed parameters of tested tubes are listed in Table 1. The objective of this study was to investigate the effect of mass flux, annulus gap, and enhancement structures on the heat transfer performance during condensation and evaporation of R134a in the annulus of a tube-in-tube heat exchanger.

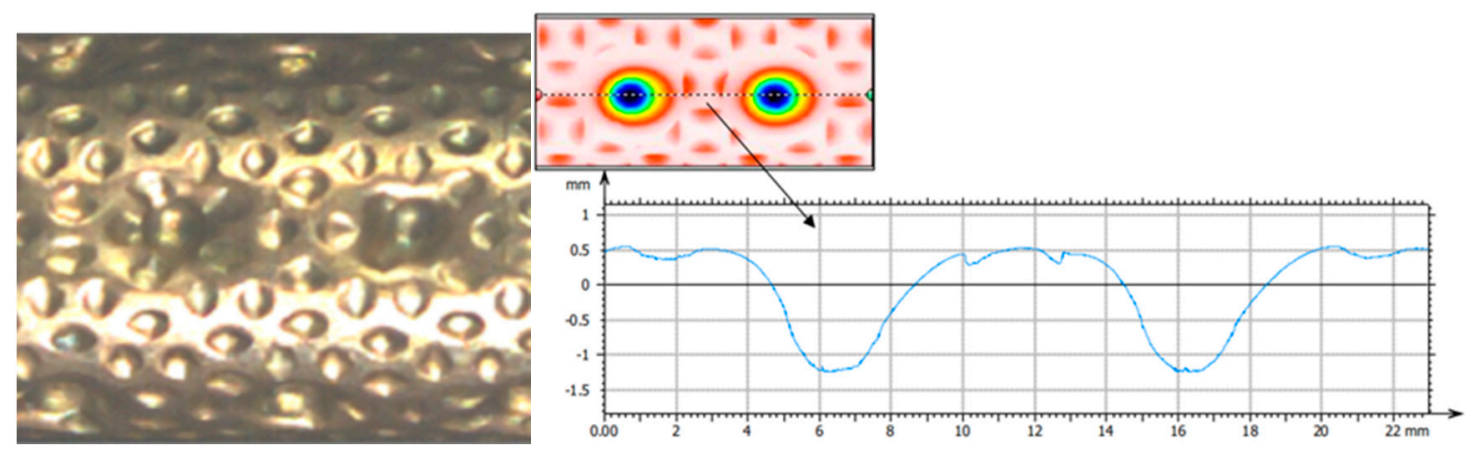

Figure 1. The external surface structure of the 1EHT tube. 
Table 1. Details of the test tubes.

\begin{tabular}{ccc}
\hline Tube Parameters & 1EHT Tube & Smooth Tube \\
\hline Internal diameter of inner tube, $d_{i}(\mathrm{~mm})$ & 17.09 & 17.09 \\
Outer diameter of inner tube, $d_{o}(\mathrm{~mm})$ & 19.05 & 19.05 \\
Average wall thickness $(\mathrm{mm})$ & 0.98 & 0.98 \\
Height of dimple/protrusion $(\mathrm{mm})$ & 1.71 & - \\
Projection diameter $(\mathrm{mm})$ & 4.4 & - \\
Dimpled/protruded pitch $(\mathrm{mm})$ & 9.86 & - \\
Helix angle, $\theta\left(^{\circ}\right)$ & 60 & 1 \\
Ratio of actual heat transfer area, $A_{E} / A_{S}$ & 1.20 & 25,26 \\
Inside diameter of outer tube, $D_{i}(\mathrm{~mm})$ & 25,26 & 2 \\
Tube length, $L(\mathrm{~m})$ & 2 & copper \\
Tube material & copper & - \\
\hline
\end{tabular}

\section{Experimental Procedure}

\subsection{Test Apparatus}

A schematic diagram of the test apparatus employed in this condensation and vaporization study is given in Figure 2a. It consisted of three fluid loops: (i) a working fluid loop containing the test section; (ii) a water circuit used for adjusting the heat input, used to regulate the vapor quality of the test section; (iii) a sub-cooled ethyl alcohol loop, used to cool the saturated two-phase refrigerant to a sub-cooled liquid at a fixed temperature.

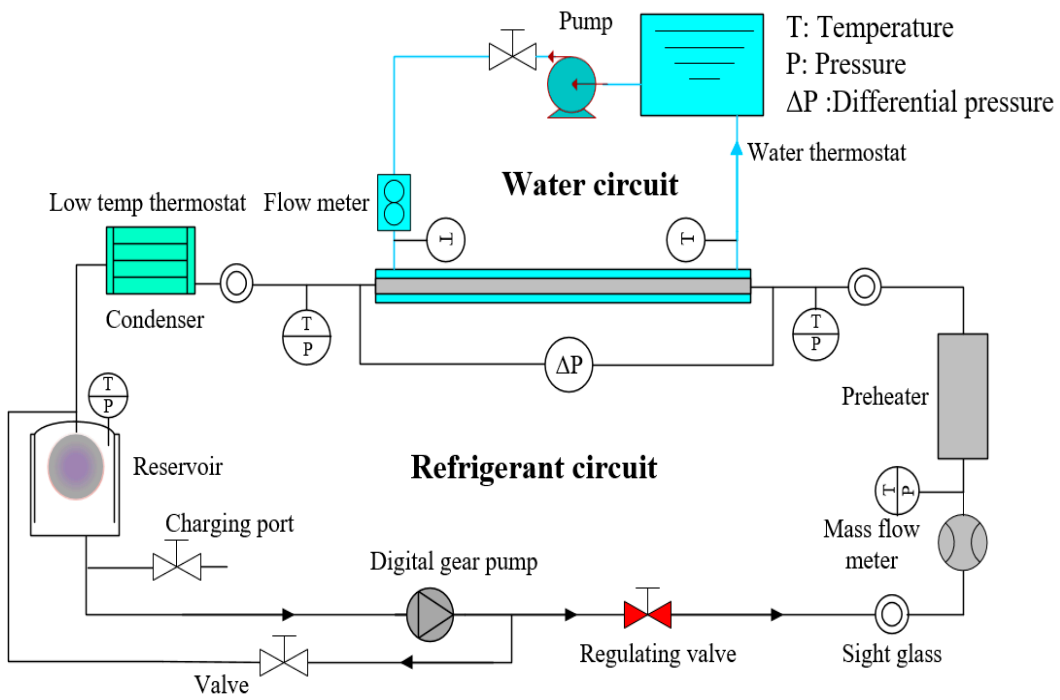

(a)

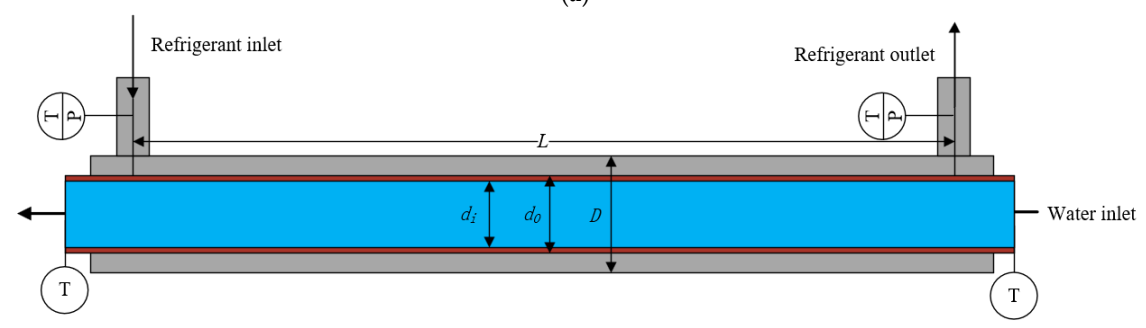

(b)

Figure 2. Schematic diagram of (a) experimental apparatus, and (b) test section.

The refrigerant loop consisted of the following components: a tube-in-tube heat exchanger (test section), condenser, reservoir, digital gear pump, flow regulator, Coriolis mass flow meter, electric 
preheater, sight glasses, and valves. The test section was manufactured as a straight, horizontal counter-flow tube heat exchanger (length of $2 \mathrm{~m}$ ). Platinum RTDs (resistance temperature detectors) were installed at the inlet and outlet of both the water side and the refrigerant side; they were able to measure the temperature with a calibrated uncertainty of $\pm 0.1 \mathrm{~K}$. Refrigerant saturation pressure was determined by a pressure transducer (Rosemount 3051) with a range of $0-5 \mathrm{MPa}$, installed at the entrance of the test section; additionally, a differential pressure transducer was employed to measure the overall pressure drop for refrigerant flows. After leaving the test section, the refrigerant flowed into a low-temperature alcohol thermostat bath; then, the two-phase refrigerant was condensed, sub-cooled, and recirculated back into the reservoir. The sub-cooled refrigerant liquid in the reservoir was then pumped into the preheater by a gear pump; the mass flux meter (between the gear pump and the electric preheater) was utilized to ensure that the actual mass flux of the refrigerant loop was within an uncertainty of $\pm 0.2 \%$ of the reading. The sub-cooled refrigerant was heated (in the preheater) by an electric heater; the electric heater was powered by a low-voltage and high-current direct current (DC) regulated power supply. The electric current varied in the range of 0-100 A with a fixed voltage of $50 \mathrm{~V}$, and a maximum power of $5 \mathrm{~kW}$ could be supplied to heat the refrigerant in the preheater. Both the voltage and the current were collected to calculate the heating power. Therefore, the outlet vapor quality at the preheater could be controlled by the current. The enthalpy of the inlet refrigerant for the preheater was determined from the temperature and pressure, which were measured using the Platinum 100 RTD and the pressure transducer. Inlet vapor quality was calculated from the heat balance of the preheater; the electric preheater was well insulated (electrically and thermally) with a heat loss fraction lower than $5 \%$, in order to ensure the accuracy of measurements. The water loop contained the tube side of the test section, a centrifugal pump, a thermostat bath, a magnetic flow meter, and a regulator valve. The heat input of the test section varied with the temperature of the thermostat bath and the water flow rates; in order to achieve the desired vapor quality, the refrigerant was heated or cooled in the test section. Additional details of the test apparatus can be obtained from Li et al. [21].

Figure $2 b$ illustrates the test section employed in this work; the test section was a double-pipe heat exchanger with an effective heat length of $2 \mathrm{~m}$. In this study, tubes with an inner diameter of $25 \mathrm{~mm}$ and $26 \mathrm{~mm}$ were employed as the outer tube in order to investigate the effect of annulus width; the tested tubes were used as the inner tube of the heat exchanger. In addition, the whole test section was well insulated, covered by a 40-mm-thick layer of polyurethane (thermal insulation), ensuring the accuracy of the experimental results. Before the evaporation and condensation experiments, the thermal insulation of the test section was verified using single-phase flow tests; the heat balance of the water side and refrigerant side in the test section and the preheater is given in Figure 3. The deviation in the heat balance between the water side and refrigerant side fell in an error band of $\pm 5 \%$; from this analysis, it is reasonable to conclude that the test section and the preheater were well insulated.

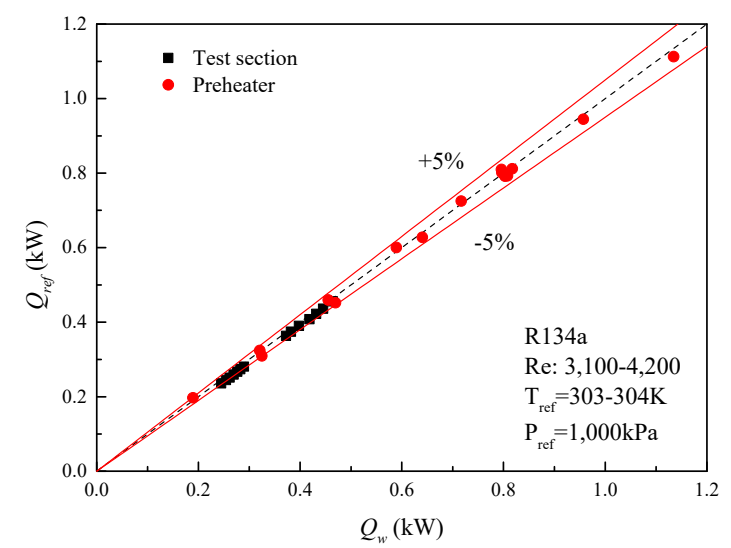

Figure 3. Heat balance measurements for single-phase flow in the smooth tube. 


\subsection{Test Conditions}

The condensation and evaporation heat transfer characteristics of annulus flow, using R134A, were investigated. During the condensation experiments, mass velocities varied in the range of $50-120 \mathrm{~kg} /\left(\mathrm{m}^{2} \cdot \mathrm{s}\right)$, with a vapor quality in the range of $0.8-0.1$. Heat flux increased with increasing mass velocities in order to keep a constant vapor quality variation for the test section. Mass velocities ranged from $40-80 \mathrm{~kg} /\left(\mathrm{m}^{2} \cdot \mathrm{s}\right)$ for the evaporation study, with the vapor quality ranging from 0.2 to 0.8 . Two different annulus gaps were considered, $2.975 \mathrm{~mm}$ and $3.475 \mathrm{~mm}$. Experimental results were sampled for a continuous period of $5 \mathrm{~min}$ (after the fluctuation of pressure was less than $3 \mathrm{kPa}$ and the temperature variation was less than $0.1 \mathrm{~K}$ ). A summary of the experimental conditions is given in Table 2.

Table 2. Experimental conditions.

\begin{tabular}{ccc}
\hline Parameters & \multicolumn{2}{c}{ Range } \\
\hline Refrigerant & R134A \\
\hline Experimental type & Evaporation & Condensation \\
\hline Saturation temperature, $T_{\text {sat }}\left({ }^{\circ} \mathrm{C}\right)$ & 6 & 45 \\
Refrigerant mass velocity, $G\left(\mathrm{~kg} / \mathrm{m}^{2} \cdot \mathrm{s}\right)$ & $30-80$ & $50-120$ \\
Heat flux, $q\left(\mathrm{~kW} / \mathrm{m}^{2}\right)$ & $9.04-15.21$ & $9.32-19.49$ \\
Average vapor quality, $x_{\text {ave }}$ & $0.35,0.5$ & $0.1-0.9$ \\
\hline
\end{tabular}

\section{Data Reduction and Uncertainty Analysis}

\subsection{Data Reduction}

Experimental data were analyzed to determine the vapor quality, heat flux, and heat transfer coefficient. The overall heat transfer rate of the test section was reduced using the conservation of heat for both the water side and refrigerant side.

$$
Q_{w}=c_{p, t s} m_{w, t s}\left(T_{w, t s, o u t}-T_{w, t s, \text { in }}\right) \mathrm{a}=1,
$$

where $c_{p, t s}$ refers to the specific heat of water taken at the average bulk temperature of the test section, $m_{w, t s}$ is the mass flow rate of tube-side water acquired by the magnetic flow meter, and $T_{w, t s, i n}$ is the water temperature at the inlet and $T_{w, t s, o u t}$ is the water temperature at the outlet of the test section. Any heat loss in the test section was minimal because of the insulation (verified by the heat loss study). Heat flux, $q$, was based on the inner surface area $A_{i}$ deduced from the internal diameter of the equivalent smooth tube, calculated using the following equation:

$$
q=Q_{w} / A_{0}
$$

Inlet vapor quality $\left(x_{i n}\right)$ was determined using the energy balance of the electric preheater. Total heat measured $\left(Q_{p h}\right)$ by the wattmeter was regarded as the heat imposed in the preheater, and it consisted of two components, sensible heat $\left(Q_{\text {sens }}\right)$ and latent heat $\left(Q_{l a t}\right)$.

$$
\begin{gathered}
Q_{p h}=\lambda_{p h} \cdot V I=Q_{l a t}+Q_{s e n s}, \\
Q_{s e n s}=c_{p, l, r e f} m_{r e f}\left(T_{s a t}-T_{r e f, p h, i n}\right), \\
Q_{l a t}=m_{r e f} h_{l v} x_{i n}, \\
x_{i n}=\frac{\lambda \cdot V I}{m_{r e f} h_{l v}}-\frac{c_{p, l, r e f}}{h_{l v}}\left(T_{s a t}-T_{r e f, p h, i n}\right),
\end{gathered}
$$


where $\lambda_{p h}, V, I, c_{p, l, r e f}, m_{r e f}, T_{r e f, p h, i n}$ and $h_{l v}$ refer to the heat conservation factor to account for heat loss of the preheater, electric voltage and current, specific heat of refrigerant obtained at the mean temperature of the preheater, mass flow rate, inlet temperature, and latent heat of the refrigerant, respectively. Accordingly, the vapor quality at the exit of the test section, $x_{\text {out }}$, was calculated as

$$
x_{\text {out }}=x_{\text {in }}-Q_{w} /\left(m_{r e f} h_{l v}\right) .
$$

Average vapor quality of the test section could be determined as

$$
x_{\text {ave }}=\frac{x_{\text {in }}+x_{\text {out }}}{2} .
$$

The logarithmic mean temperature difference between the tube side and annulus was determined from the inlet and exit temperatures of refrigerant and water.

$$
\text { LMTD }=\frac{\left(T_{r e f, t s, \text { out }}-T_{w, \text { ts }, \text { in }}\right)-\left(T_{r e f, t s, \text { in }}-T_{w, \text { ts out }}\right)}{\ln \left[\left(T_{r e f, t s, \text { out }}-T_{w, \text { ts, in }}\right) /\left(T_{r e f, \text { ts, in }}-T_{w, t s, \text { out }}\right)\right]},
$$

where $T_{r e f, t s, \text { in }}$ and $T_{\text {ref }, t s, o u t}$ refer to the inlet and outlet temperature of the refrigerant in the annulus, while $T_{w, t s, i n}$ and $T_{w, t s, o u t}$ refer to the inlet and exit temperatures in the water. Assuming that there was no fouling resistance for the internal surface of the tube, the heat transfer coefficient $\left(h_{r e f}\right)$ for condensation and evaporation was deduced from the following equation:

$$
h_{r e f, o}=\frac{1}{A_{o}\left[\frac{\mathrm{LMTD}}{Q_{w}}-\frac{1}{h_{w, i} A_{i}}-\frac{\ln \left(d_{o} / d_{i}\right)}{2 \pi L \cdot k}\right]},
$$

where $A_{i}$ and $A_{o}$ refer to the tube-side and shell-side heat transfer areas, respectively, $d_{i}$ and $d_{o}$ are the internal and external diameters of the tested tubes, and $k$ is the thermal conductivity of the tube wall. It is worth noting that $A_{i}$ and $A_{o}$ for the enhanced tubes were determined using the nominal inner and outer diameter of test tubes.

Extensive experimental investigations showed that the Gnielinski [22] correlation can accurately predict the convective heat transfer coefficients in a plain tube or annulus, and the correlation is valid in the range $3000<R e_{w}<5 \times 10^{6}$ and $0.5<P r_{w}<2000$; this covers the present test conditions. Therefore, the Gnielinski [22] correlation was utilized to predict the in-tube heat transfer coefficients, $h_{w}$, for the smooth tube.

$$
h_{w}=\frac{(f / 2)\left(R e_{w}-1000\right) P r_{w}}{1+12.7(f / 2)^{0.5}\left(\operatorname{Pr}_{w}^{2 / 3}-1\right)}\left(\frac{\mu_{b u l k}}{\mu_{w a l l}}\right)^{0.14} \frac{k_{w}}{d_{w}} .
$$

The ratio, $\left(\mu_{\text {bulk }} / \mu_{\text {wall }}\right)^{0.14}$ accounts for the influence of viscosity at the water bulk and the internal wall temperature; thermal conductivity $\left(k_{w}\right)$ values were determined at the mean temperature of the water. Fanning friction factor, $f$, was predicted by the Petukhov correlation [23] for plain tubes, which is applicable for $3000<R e_{w}<5 \times 10^{6}$, and is given by

$$
f=\left(1.58 \ln R e_{w}-3.28\right)^{-2} .
$$

However, the above predictive procedures were inappropriate to use with the 1EHT tube since the inner surface of 1EHT tube was modified with enhancement patterns. Therefore, Wilson plot tests were used to calculate the water-side heat transfer coefficients $h_{w}$. The overall thermal resistance of the test section for the 1EHT tube was calculated as follows:

$$
\frac{1}{h_{t s}}=\frac{d_{o}}{a h_{w} d_{i}}+\frac{1}{h_{r e f}}+\frac{d_{o} \ln \left(d_{o} / d_{i}\right)}{2 k}
$$


where $h_{t s}$ refers to the total heat transfer coefficient of the test section, and $a$ represents the in-tube heat transfer enhancement ratio (EHT tube compared to an equivalent plain tube). During the Wilson plot tests, the refrigerant mass flow rate was fixed at a relatively large value in order to minimize the experimental error; mass flow rate and the temperature of water were adjusted to obtain a linear relationship between the water-side thermal resistance and the overall resistance. The Wilson plot results for the 1EHT tube are given in Table 1.

All the thermal and transport properties of the refrigerant in the analysis were acquired from REFPROP 9.0, which was developed and released by NIST (National Institute of Standards and Technology). [24]; all the instruments including pressure transducers, Platinum 100 RTDs, and mass flow meters in the test apparatus were calibrated according to an NIST traceable standard.

\subsection{Experimental Uncertainty Analysis}

The measurement of the heat transfer coefficient depends on the test conditions and accuracy of the instruments. In this study, an uncertainty analysis was conducted according to the error propagation method given in Moffat [25]. Using this analysis, the relative uncertainty $\left(U_{R}\right)$ of the dependent parameters could be calculated using the experimental uncertainty for the primary measurements, and it was estimated using the following equation:

$$
U_{R}=\left[\sum_{i=1}^{n}\left(\frac{\partial R}{\partial X_{i}} U\left(X_{i}\right)\right)^{2}\right]^{1 / 2}
$$

The results are summarized in Table 3 for the relative uncertainties and the accuracy of various parameters. A maximum uncertainty of the heat transfer coefficient was found to be $12.12 \%$ for this study.

\subsection{Experimental Validation}

Single-phase heat transfer experiments were conducted for the validation of test procedures. Figure 4 depicts the relationship between the heat transfer coefficient and the Reynolds number. The single-phase experiment was conducted using R134a and R410A in the turbulent regime to validate the present test procedure. The average temperature along the test section was kept in the range of 303-304 K, and the ambient temperature was controlled at $298 \mathrm{~K}$ by an air-conditioner. The results were compared against the Gneilinski [22] correlation and the Dittus-Bolter correlation. All the data points could be predicted within $\pm 10 \%$ by the Gneilinski [22] correlation. The EHT tube could produce a single-phase heat transfer enhancement ratio of 1.45-1.76 for the present test conditions compared to the smooth tube. In addition, a series of repetitive experiments were conducted using R410A to validate the present test procedure, and the tube-in-tube heat exchanger with $D_{h}=6.95 \mathrm{~mm}$ was employed. The same tube-in-tube heat exchanger made of the smooth tube was used for the further experiments of R134a. Two experiments were carried out on two different days for the flow boiling heat transfer performance in the annulus of the smooth tube. The inlet and the outlet vapor quality were fixed at 0.2 and 0.8 , respectively. Figure 5 demonstrates a comparison of the two results, and good agreement was found between them. Therefore, it is reasonable to conclude that the results in this study have good repeatability. 
Table 3. Uncertainties of measured and calculated parameters.

\begin{tabular}{cc}
\hline Measured Parameters & Accuracy \\
\hline Diameter & $\pm 0.05 \mathrm{~mm}$ \\
Length & $\pm 0.5 \mathrm{~mm}$ \\
Temperature & $\pm 0.1 \mathrm{~K}$ \\
Pressure, range: $0-5000 \mathrm{kPa}$ & $\pm 0.075 \%$ of full scale \\
Differential pressure, range: $0-50 \mathrm{kPa}$ & $\pm 0.075 \%$ of full scale \\
Refrigerant mass flow rate, range: $0-120 \mathrm{~kg} / \mathrm{h}$ & $\pm 0.2 \%$ of reading \\
Water mass flow rate, range: $0-600 \mathrm{~kg} / \mathrm{h}$ & $\pm 0.2 \%$ of reading \\
\hline Calculated Parameters & Uncertainty \\
\hline Mass velocity, $\mathrm{G}\left(\mathrm{kg} / \mathrm{m}^{2} \cdot \mathrm{s}\right)$ & $\pm 1.17 \%$ \\
Heat flux, $q\left(\mathrm{~kW} / \mathrm{m}^{2}\right)$ & $\pm 2.64 \%$ \\
Vapor quality, $x$ & $\pm 4.12 \%$ \\
\hline Heat transfer coefficient, $h_{r e f}\left(\mathrm{~W} / \mathrm{m}^{2} \cdot \mathrm{K}\right)$ & $\pm 12.12 \%$ \\
\hline
\end{tabular}

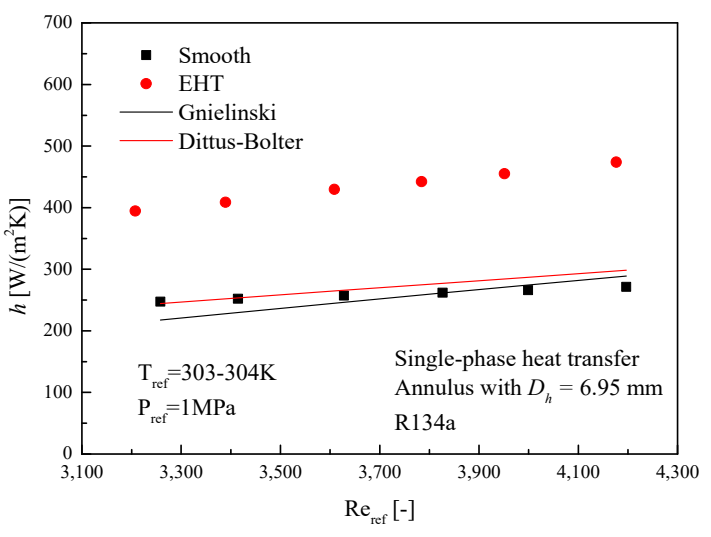

(a)

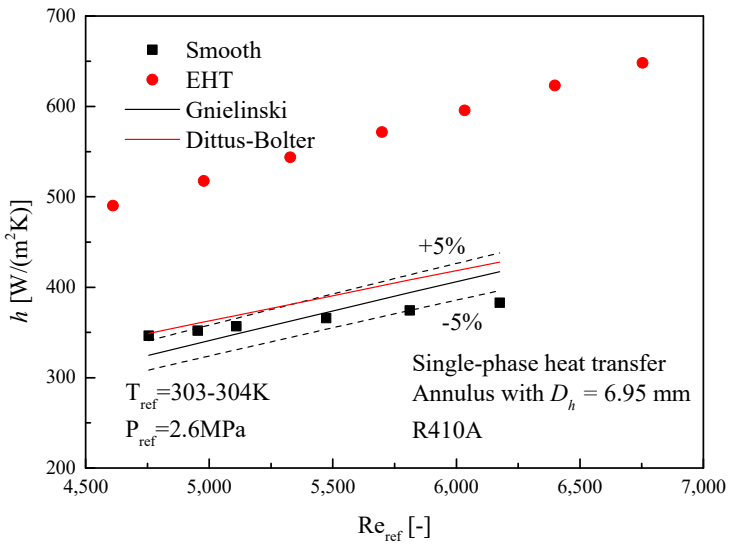

(b)

Figure 4. Variation of the single-phase heat transfer coefficient as a function of Reynolds number, and comparison against Gneilinski [22] and Dittus-Bolter correlation using work fluids: (a) R134a; (b) R410A.

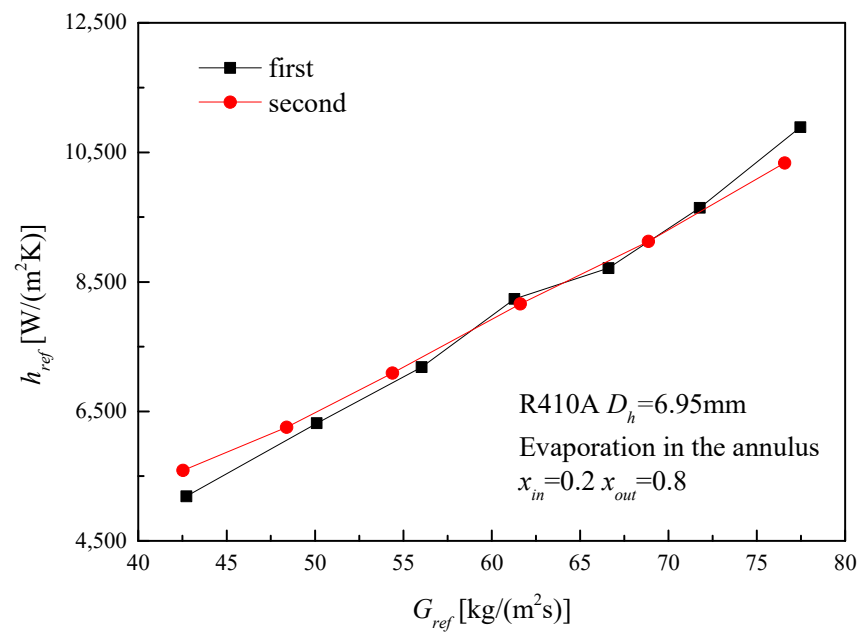

Figure 5. Repetitive experiments conducted for the flow boiling of R410A in the annulus with a hydraulic diameter of $6.95 \mathrm{~mm}$. 


\section{Results and Discussion}

\subsection{Heat Transfer Characteristics of Condensation}

In the condensation study, two test sections with different inner diameters of the outer tube were employed to investigate the influence of the annulus gap. The relationship of the condensation heat transfer and mass velocity is given in Figure 6a; the corresponding heat flux values are also given in Figure $6 \mathrm{~b}$ for a comparison. These results differ from similar experimental investigations reported by Tang and $\mathrm{Li}$ [18] and Chen et al. [26]; the results of the present study show that the heat transfer coefficient increased with increasing mass flux, implying that the convective condensation component occupied an important role in the overall heat transfer for the present test conditions. Additionally, increased mass fluxes could also improve the interfacial shear stress and move the accumulated condensate at the bottom of the annulus to the upper part, improving the overall performance.

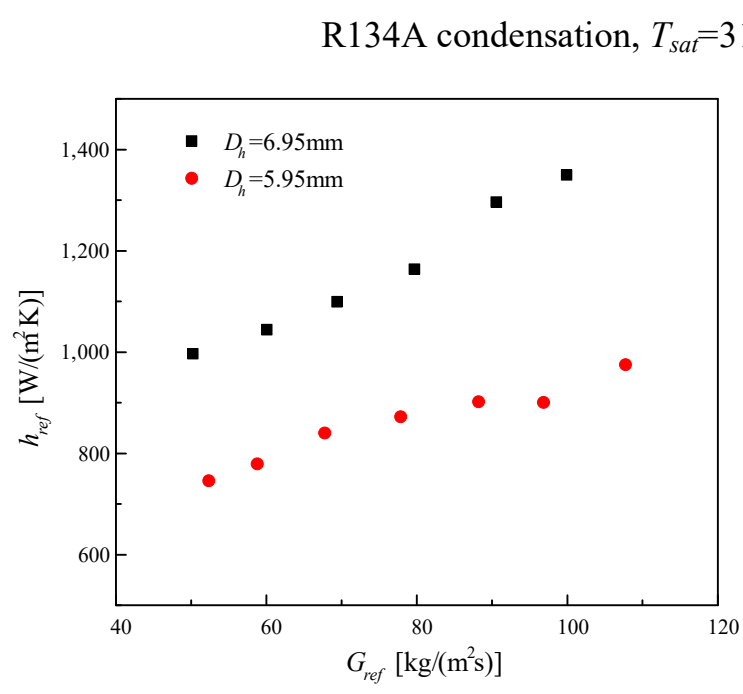

(a)

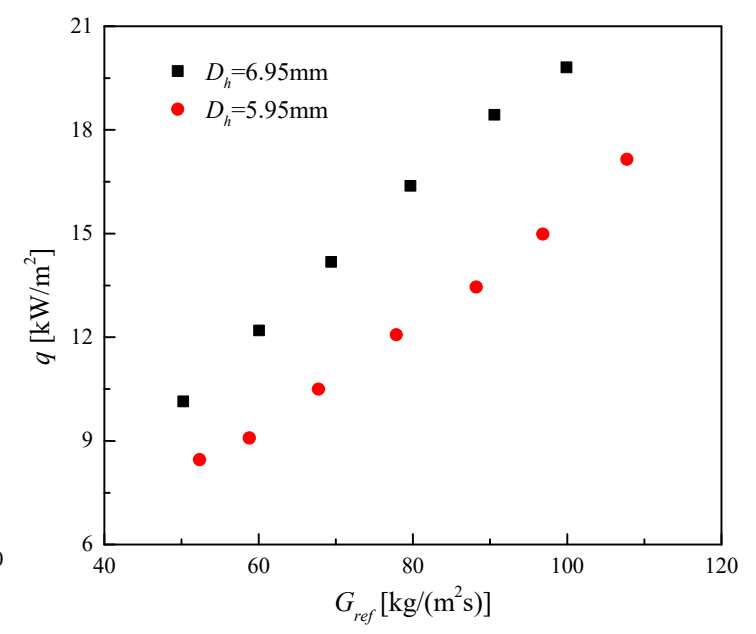

(b)

Figure 6. Variation of (a) heat transfer coefficient and (b) heat flux as a function of mass flux during condensation for a smooth tube with a different annulus spacing.

The heat transfer coefficient for the wide annulus case showed heat transfer that was approximately $33 \%$ to $50 \%$ larger than the narrow annulus case; this can be attributed to the improvement of the convective heat transfer. According to Cavallini et al. [27], the in-tube condensation flow patterns can be divided into two types: $\Delta \mathrm{T}$-dependent flow and $\Delta \mathrm{T}$-independent flow; in a horizontal tube, $\Delta \mathrm{T}$-dependent flow occurs when gravity is the dominant force. A similar classification can be applied to the annulus condensation cases; they all fall into the $\Delta \mathrm{T}$-dependent flow case due to the relatively low mass fluxes and large channel gap dimensions. For the $\Delta \mathrm{T}$-dependent flow case, the film condensation heat transfer component and the convective heat transfer component should be included in order to achieve an accurate prediction. Chen [28] solved the boundary layer equation for laminar film condensation of quiescent vapor on a single horizontal smooth tube; the theoretical equation for the heat transfer coefficient was given as

$$
h_{o}=0.728\left(\frac{\rho_{l}\left(\rho_{l}-\rho_{g}\right) g h_{l v} k_{l}^{3}}{\mu_{l} d_{o}\left(T_{\text {sat }}-T_{\text {wall }}\right)}\right)^{1 / 4},
$$

where the physical properties are acquired at the mean temperature between the wall and the saturation temperature of the refrigerant. Tang and Li [18] introduced a modified heat transfer equation that 
could be used to predict the present data; this model added a retention angle, $\alpha$, into the Chen [28] equation in order to account for the effect of vapor quality.

It should be noted that the average vapor quality along the test section was employed for the prediction of heat transfer coefficients for simplification. In addition, little difference was found between the predicted values calculated from average vapor quality and the average value in the vapor quality range. The comparison between the experimental and predicted values of Chen [28] and Tang and $\mathrm{Li}$ [18] correlation is illustrated in Figure 7. There was an obvious deviation between $h_{\text {exp }}$ and $h_{\text {pre }}$ for the Chen correlation; all these data points were overpredicted with a mean absolute deviation (MAD) of $42.5 \%$. When using the Tang and Li [18] correlation, an acceptable prediction was given with a MAD of $7.9 \% ; 84.6 \%$ of the data points could be predicted in an error band of $\pm 30 \%$. However, neither of the above correlations could accurately predict the variation of the heat transfer coefficient versus mass flux, which would be an important contribution to the thermal performance during condensation in the annulus. Additional investigations and experimental data are demanded to explore the heat transfer mechanisms during this phenomenon.

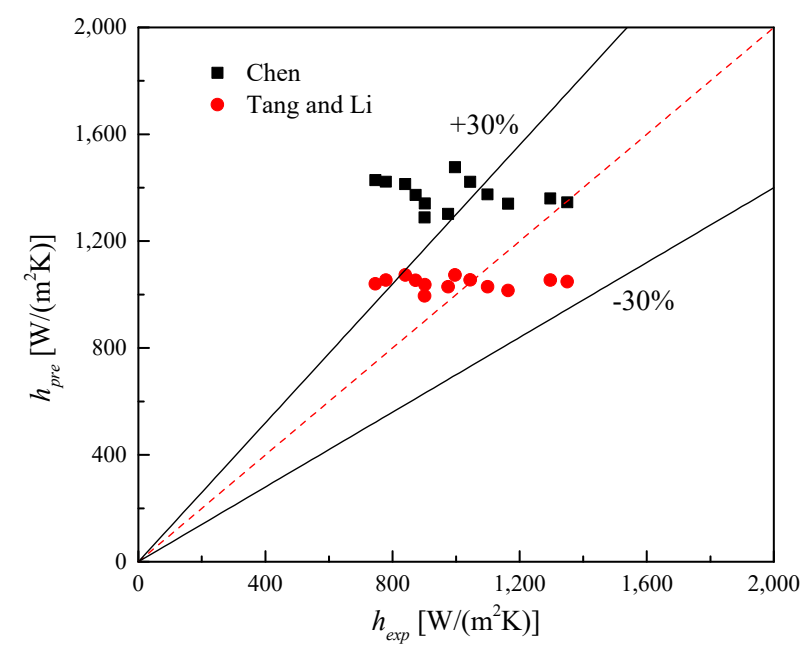

Figure 7. Prediction of Chen, and Tang and Li [18] correlation against the present data for condensation on the smooth tube.

Values of the MAD were determined as follows:

$$
\mathrm{MAD}=\frac{1}{N} \sum_{1}^{N} \frac{\left|h_{\exp }-h_{\text {pre }}\right|}{h_{\exp }} \times 100 \% .
$$

Figure 8a shows the variation of the heat transfer coefficient with mass flux during condensation on the outside of the 1EHT tube in the annulus; results were compared to the smooth tube. Figure 8b provides the heat flux variation for all of the test conditions. As can be seen, there was little variation between the 1EHT tube and the smooth tube; therefore, it is reasonable to compare their thermal performance under the same mass flux. It should be noted that all the results in Figure 8 were acquired for condensation in an annulus with an outer diameter $D_{i}=25 \mathrm{~mm}$, with the heat flux ranging from $8-18 \mathrm{~kW} / \mathrm{m}^{2}$. The results demonstrate that the 1EHT tube provided an enhancement to the annulus condensation heat transfer performance (when compared to a smooth tube) in the range of $98-178 \%$. According to Chen et al. [28], the superior performance of the 1EHT tube for condensation in an annulus was explained by the turbulence and flow pattern change caused by the enhanced surface structure. Additionally, surface tension might be a dominant contributor to the condensation heat transfer for $\mathrm{G}_{\mathrm{ref}}<50 \mathrm{~kg} /\left(\mathrm{m}^{2} \cdot \mathrm{s}\right)$. Tang and $\mathrm{Li}[18]$ concluded that increasing the mass flux in the annulus may change the flow pattern; two possible flow patterns are given in Figure 9. Generally, the cross-sectional liquid distribution depends on the joint actions of three forces, including gravity, surface tension, and 
shear stress. At low mass fluxes, the condensate would accumulate at the bottom due to gravity being dominant; as the mass flux increases, shear stress begins to have a greater influence. In addition, the specific structures of the external tube surface can augment the convective heat transfer and begin to produce more turbulence, fluid mixing enhancement, boundary layer disruption, and creation of secondary flows.

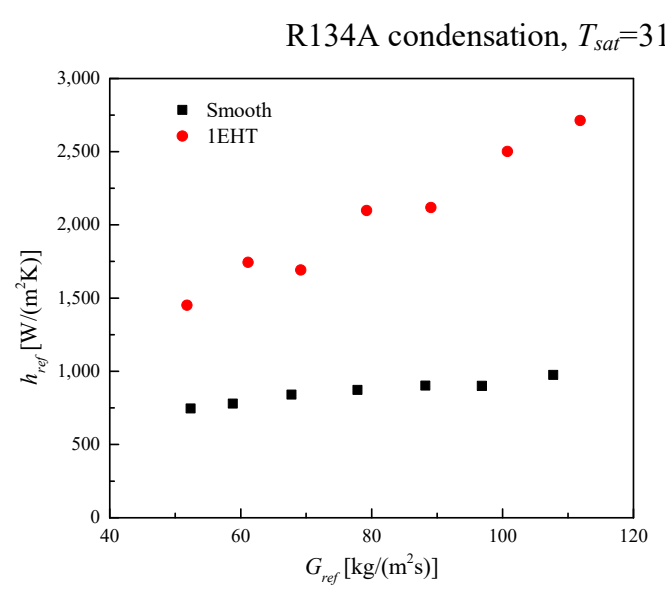

(a)

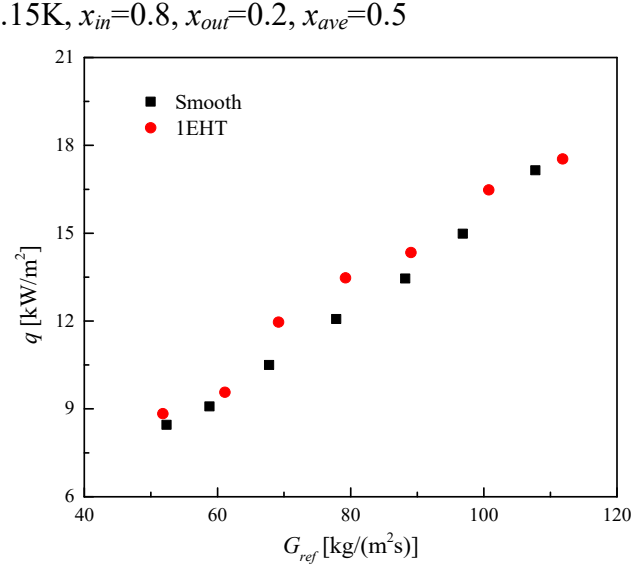

(b)

Figure 8. Variation of (a) heat transfer coefficient and (b) heat flux as a function of mass flux during condensation on the 1EHT tube in the annulus with $D_{h}=5.95 \mathrm{~mm}$ compared to a smooth tube.

The effect of vapor quality on the condensation characteristics in the annulus was also investigated at fixed mass velocities $G_{r e f}=80 \mathrm{~kg} /\left(\mathrm{m}^{2} \cdot \mathrm{s}\right)$ and $G_{r e f}=100 \mathrm{~kg} /\left(\mathrm{m}^{2} \cdot \mathrm{s}\right)$; results are given in Figure 10a. The results indicate that the heat transfer coefficient increased rapidly with increasing vapor quality, especially for the vapor quality $x_{\text {ave }}<0.6$, and the thermal performance of the 1EHT tube at $G_{r e f}=80 \mathrm{~kg} /\left(\mathrm{m}^{2} \cdot \mathrm{s}\right)$ was slightly worse than that at $G_{r e f}=100 \mathrm{~kg} /\left(\mathrm{m}^{2} \cdot \mathrm{s}\right)$. The steep slope for the heat transfer coefficient versus vapor quality resulted from the increasing cross-sectional void fraction; the condensate redistributed circumferentially and produced a decrease in the average film thickness on the tube. Figure $10 \mathrm{~b}$ shows that the heat flux was fixed in a narrow range of $3-5 \mathrm{~kW} / \mathrm{m}^{2}$. Heat transfer coefficients at $x_{\text {ave }}=0.5$ were nearly two times higher than those data points in Figure 8a at the same mass flux. This could have been caused by the increased film thermal resistance on the external surface of 1EHT tube with the increased heat flux. The negative relationship between heat transfer coefficient and heat flux seems to have a steeper slope than predicted in the Chen et al. [28] and Tang and Li [18] correlation. The steeper slope may be attributed to the increasing condensate on the tube, and the severely flooded dimples on the surface with increasing heat flux. Generally, gravity causes the condensate on the surface to flow down the tube and accumulate at the bottom of the annulus; however, increased heat flux and dimples may increase the film thickness and degrade the thermal performance.

\subsection{Heat Transfer Characteristics of Evaporation}

As shown in Figure 11a, the heat transfer coefficient for evaporation of R134A in the annulus, using the smaller outer tube (inside diameter $D_{i}=25 \mathrm{~mm}$ ), increased gradually as the mass flux increased. Different vapor quality ranges were employed for the evaporation experiments, and the average vapor quality was kept at 0.35 and 0.5 . Little differences were found between the two series of results; the deviation fell within the range of experimental uncertainties. Generally speaking, the flow boiling heat transfer can be divided into two parts: (i) convective boiling and (ii) nucleate boiling heat transfer; nucleate boiling heat transfer increases with increasing heat fluxes (as detailed in Cooper [29]). For in-tube flow boiling in this study, the targeted mass velocity fell in (i) the stratified flow regimes at higher vapor qualities, and (ii) slug flow at lower vapor qualities. For relatively high 
vapor qualities, gravity dominates the liquid distribution; this results in a thin liquid film or even only a gas phase on the upper part of the annulus, which decreases the effective flow boiling heat transfer area and causes heat transfer deterioration. Slug flow might exist at low vapor qualities; the transitional vapor quality between the two flow patterns is similar to the intermittent annular flow described by Wojtan et al. [30], and $\mathrm{x}_{\mathrm{I}-\mathrm{A}}$ was determined to be 0.32 . The heat transfer coefficient would drop rapidly near the transitional vapor quality due to the flow pattern change. Experiments were also conducted to explore the influence of vapor quality and heat flux on the flow boiling heat transfer coefficient with an annular hydraulic diameter of $D_{h}=5.95 \mathrm{~mm}$. The results were obtained by keeping the vapor quality of the test section in the ranges of $0.2-0.8$ and $0.1-0.8$. As shown in Figure $11 \mathrm{~b}$, the heat transfer coefficients for $x_{\text {ave }}=0.5$ were slightly higher than those for $x_{\text {ave }}=0.45$. The effect of annulus width was also investigated under similar test conditions, with a fixed average vapor quality for the test section of 0.5 . The heat transfer coefficient for the narrower annulus gap seems to be a little higher than that of the wider annulus gap; little difference was found, indicating that the annulus width may be less important for flow boiling heat transfer performance than for condensation heat transfer, due to the dominance of nucleate boiling for the test conditions.

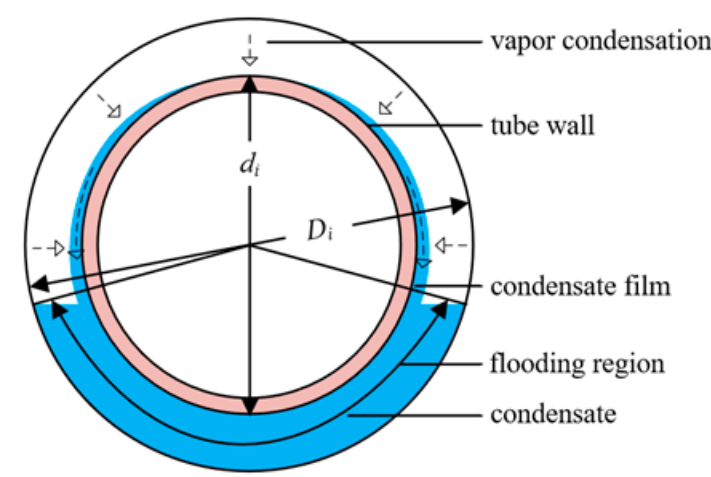

(a)

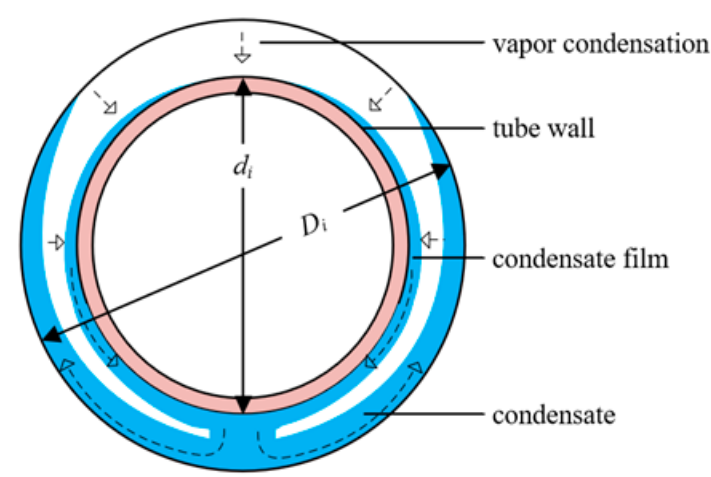

(b)

Figure 9. Schematic diagram of the possible flow pattern during condensation in the annulus for (a) low mass flux rates, and (b) large mass flux rates [18].

R134A condensation, $T_{\text {sat }}=318.15 \mathrm{~K}, x_{\text {ave }}=0.2-0.8$

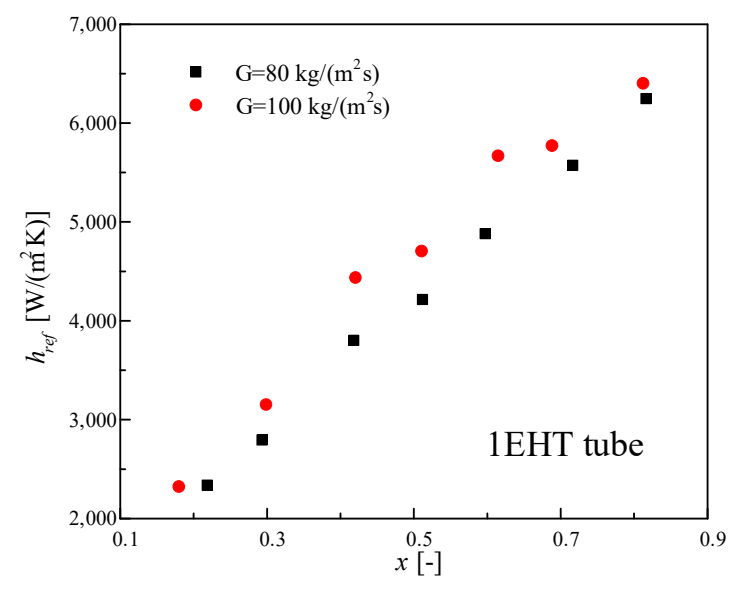

(a)

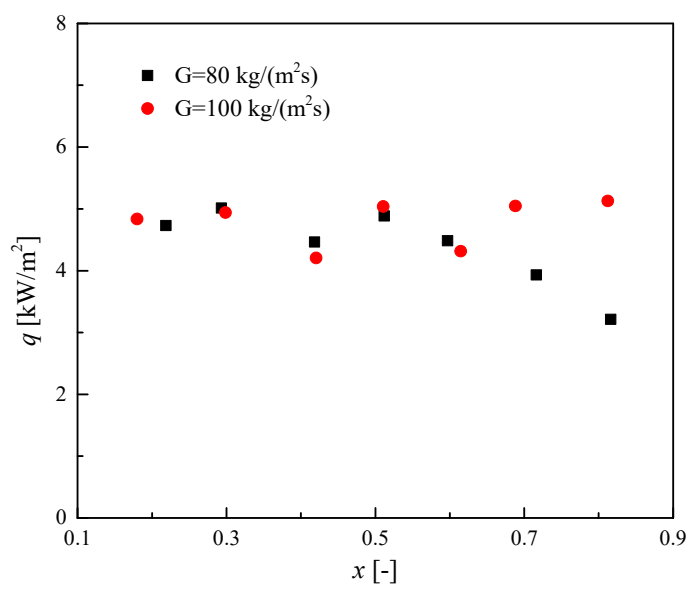

(b)

Figure 10. Variation of (a) heat transfer coefficient and (b) heat flux as a function of vapor quality for $G_{r e f}=80 \mathrm{~kg} /\left(\mathrm{m}^{2} \cdot \mathrm{s}\right)$ and $G_{r e f}=100 \mathrm{~kg} /\left(\mathrm{m}^{2} \cdot \mathrm{s}\right)$ with $D_{h}=5.95 \mathrm{~mm}$. 
R134A evaporation, $T_{\text {sat }}=279.15 \mathrm{~K}$
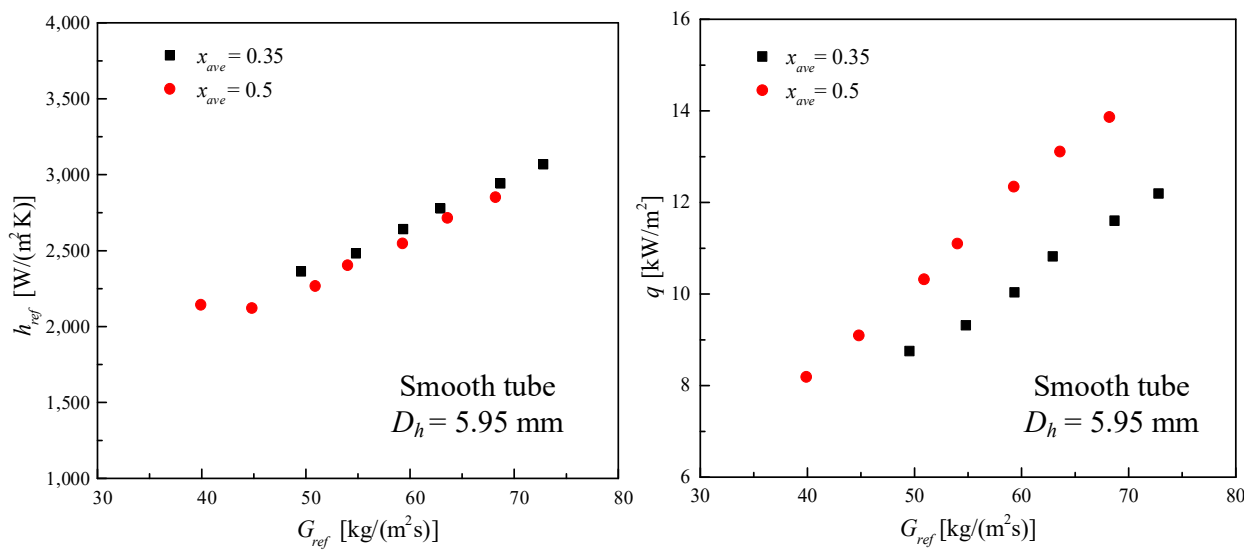

(a)

R134A evaporation, $T_{\text {sat }}=279.15 \mathrm{~K}$
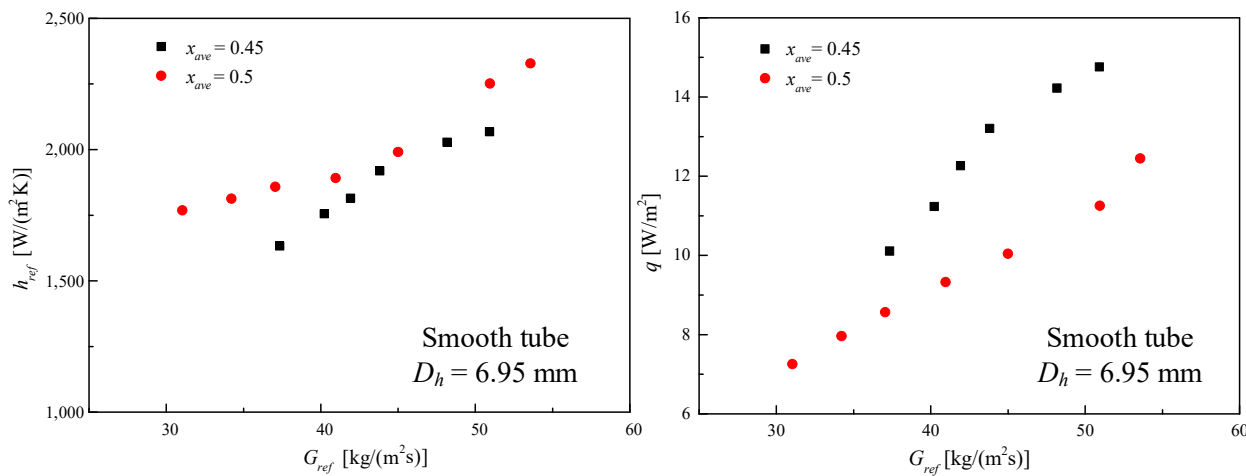

(b)

R134A evaporation, $\mathrm{T}_{\text {sat }}=279.15 \mathrm{~K}, x_{\text {ave }}=0.5$
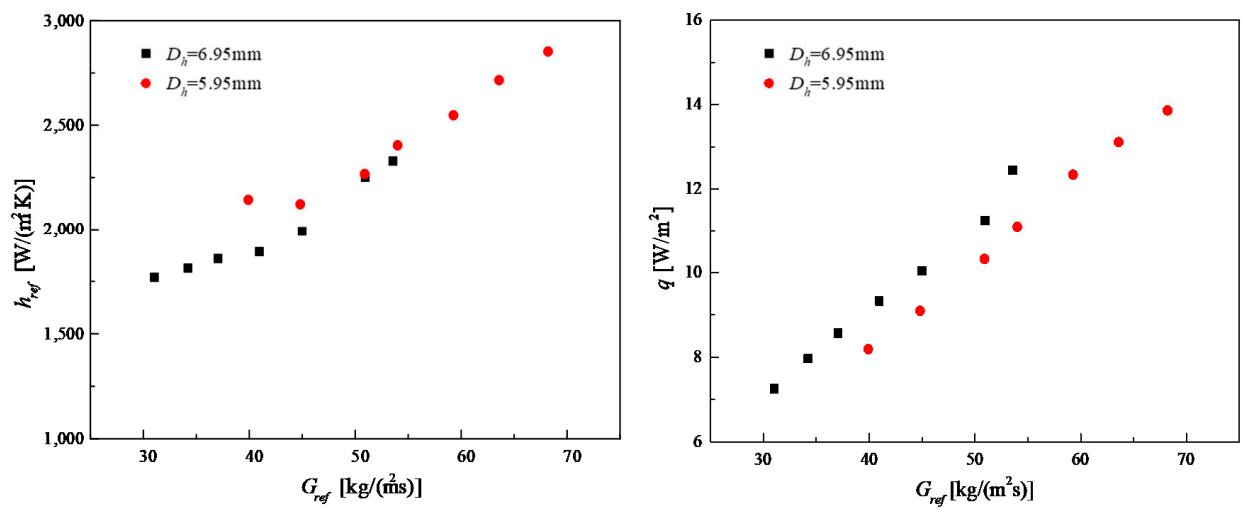

(c)

Figure 11. Variation of heat transfer coefficient and heat flux as a function of mass flux for (a) a hydraulic diameter, $D_{h}=5.95 \mathrm{~mm}$ with average vapor qualities of 0.35 and 0.5 , (b) a hydraulic diameter, $D_{h}=6.95 \mathrm{~mm}$ with average vapor qualities of 0.45 and 0.5 , and (c) hydraulic diameters, $D_{h}=5.95 \mathrm{~mm}$ and $6.95 \mathrm{~mm}$.

The effect of mass velocities on the heat transfer performance was investigated with fixed average vapor qualities of 0.35 and 0.5; results are given in Figure 12. Figure 12a shows the heat transfer coefficient during flow boiling in the annulus of the 1EHT tube for $x_{\text {ave }}=0.35$ (see Figure 12a); the heat transfer coefficient was enhanced by 11-36\% when compared to the smooth tube. The heat transfer coefficient of the 1EHT tube increased with increasing mass velocities and heat flux. For $x_{\text {ave }}=0.5$ 
(see Figure 12b), the performance of the 1EHT tube was not as good as the smooth tube at the tested mass velocities. The strange heat transfer performance of the 1EHT tube can be attributed to the enhanced external surface structure which consisted of depression and micro-pit arrays. The depression increases flow turbulence and enhances fluid mixing for single-phase flow; it would be reasonable to conclude that the droplet entrainment and interfacial phase mixing can be greatly enhanced by the depression. At a relatively high vapor quality, the liquid phase on the upper part of the annulus would accumulate in the large cavities; this would result in decreased film thickness for other parts of the surface without cavities. As mentioned previously, the stratified flow in the annulus may be less than the heat transfer performance of the upper part, with an accumulation of liquid phase in the large cavities. This may decrease the effective flow boiling heat transfer area for flow boiling, since nucleate flow boiling occurs only on the interface between the wall and liquid phase. A similar in-tube experimental investigation was conducted by Chen et al. [31], with their results indicating that the heat transfer coefficient decreased with increasing vapor qualities, especially when the vapor quality exceeded the transitional vapor quality between stratified-wavy flow and slug/stratified flow; the transitional vapor quality for the enhanced tubes was higher than that for the smooth tube. Similarly, the flow patterns in this study may change from slug/stratified flow to stratified-wavy flow for $x_{\text {ave }}$ $=0.35$ and $x_{\text {ave }}=0.5$; the heat transfer performance can be seen to deteriorate. More experimental investigations are demanded to explore the complex interaction between enhanced structures, liquid distribution, and the flow pattern transition during flow boiling in the annulus.

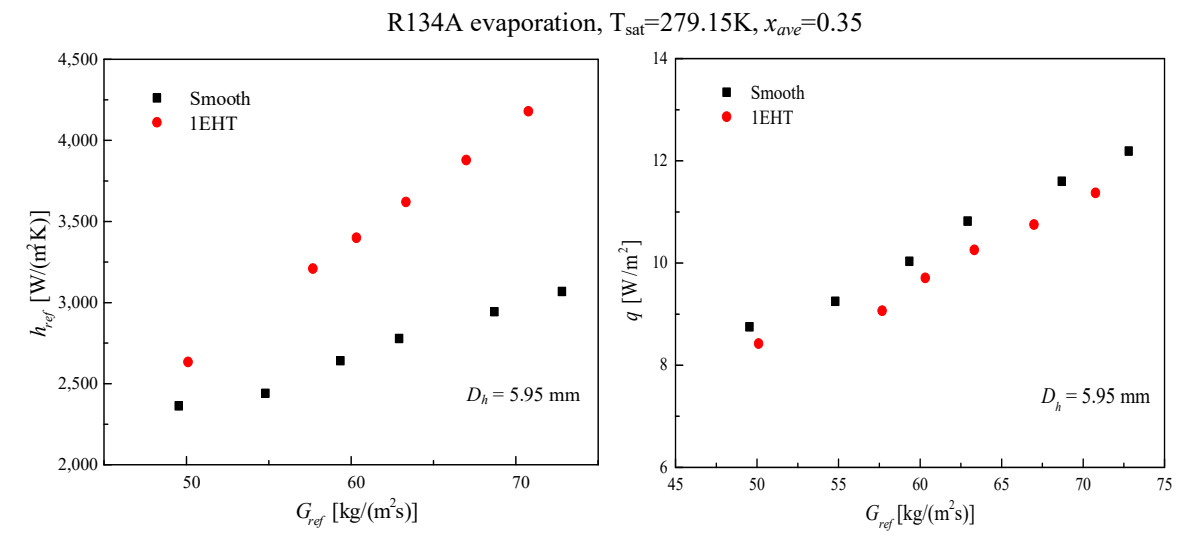

(a)

R134A evaporation, $\mathrm{T}_{\text {sat }}=279.15 \mathrm{~K}, x_{\text {ave }}=0.5$
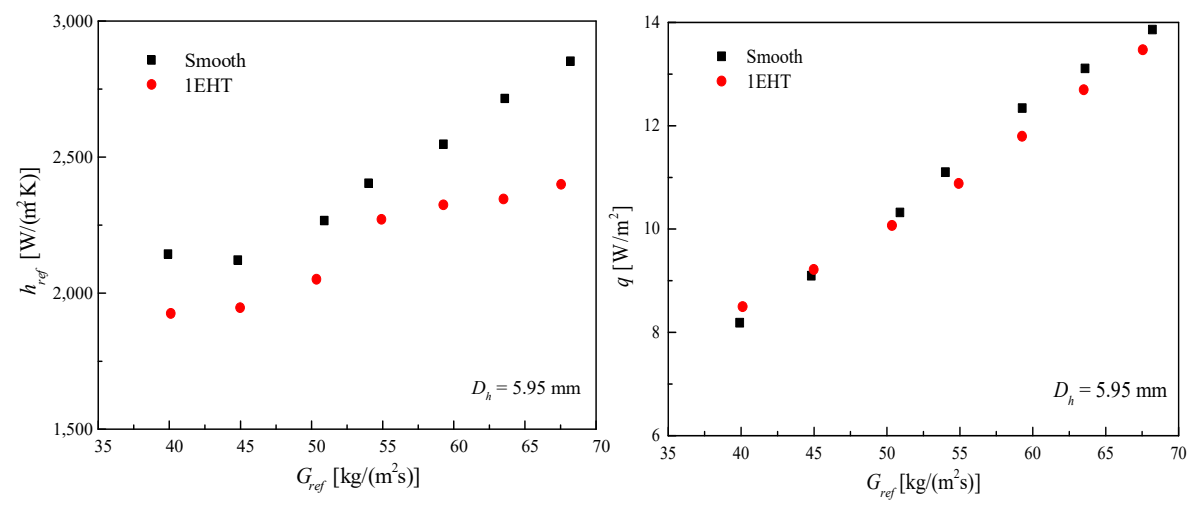

(b)

Figure 12. Variation of heat transfer coefficient and heat flux as a function of mass flux for the smooth and 1EHT tubes at (a) $x_{\text {ave }}=0.35$, and (b) $x_{\text {ave }}=0.5$. 


\section{Conclusions}

An experimental investigation of the heat transfer characteristics during flow boiling and condensation of R134A in the annulus of the 1EHT tube and an equivalent smooth tube was carried out. The experiments were conducted at a constant saturation temperature of $318.15 \mathrm{~K}$, and the effects of mass velocities, annulus width (gap), and vapor quality on the heat transfer coefficients were investigated and discussed. Several conclusions can be drawn, as outlined below.

1. The heat transfer coefficient increased with increasing mass velocities for both the smooth tube and the 1EHT tube. For condensation in the annulus of the smooth tube, the heat transfer coefficient in the wider annulus gap could achieve approximately $33 \%$ to $50 \%$ higher values than those found in the narrow gap; a reasonable prediction for a smooth tube was given by Tang and Li [18] correlation, with $84.6 \%$ of the data points falling in an error band of $\pm 30 \%$.

2. In considering condensation in the annulus of the 1EHT tube, the 1EHT tube could greatly enhance the condensation heat transfer performance in an annulus compared to a smooth tube, and heat transfer enhancement in the range of $98-178 \%$ was seen. Furthermore, the heat transfer coefficient seemed to increase rapidly with increasing mass velocities due to the re-distribution of condensate along the circumference and the decreased liquid film thickness on the tube.

3. For flow boiling in the annulus of the smooth tube, the heat transfer coefficient for evaporation of R134A in the smaller annulus gap (for $D_{h}=5.95 \mathrm{~mm}$ ) increased gradually with increasing mass flux; little difference was found between the heat performance of $x_{\text {ave }}=0.35$ and $x_{\text {ave }}=0.5$, with the latter being a little lower than the former.

4. For flow boiling in the annulus of the 1EHT tube, the heat transfer coefficient during flow boiling was enhanced by $11-36 \%$ compared to the smooth tube at $x_{\text {ave }}=0.35$; however, the heat transfer performance of the 1EHT tube was smaller than that of the smooth tube at $x_{\text {ave }}=0.5$. The heat transfer deterioration can be explained by a decrease in the effective nucleate flow boiling heat transfer area. This takes place because the flooded dimples are at a relatively high vapor quality, and a flow pattern transition takes place from slug/wavy-stratified flow to wavy-stratified flow. The results indicate that the unique enhancement units in this study may be inapplicable for the enhancement of wavy-stratified flow during flow boiling.

Author Contributions: Conceptualization, W.T. and D.J.K.; methodology, W.T., and R.S.; software, W.T.; validation, W.T.; formal analysis, D.J.K.; investigation, W.T.; resources, D.J.K., and R.S.; data curation, W.T.; writing一original draft preparation, W.T.; writing — review and editing, D.J.K., and W.L.; visualization, W.T.; supervision, D.J.K., R.S. and W.L.; project administration, D.J.K., and W.L.; funding acquisition, D.J.K., R.S. and W.L. All authors have read and agreed to the published version of the manuscript.

Funding: This work was supported by the National Science Foundation of Zhejiang Province (LY19E060004).

Conflicts of Interest: The authors declare no conflicts of interest.

\section{Nomenclature}

$A_{a}$

$A_{i}$

$A_{0}$

$c_{p}$

$d_{i}$

$d_{0}$

$D_{i}$

$D_{h}$

$f$

$g$

G actual heat transfer area, $\mathrm{m}^{2}$ inner surface area of test tube, $\mathrm{m}^{2}$ outer surface area of test tube, $\mathrm{m}^{2}$ specific heat, $\mathrm{J} /(\mathrm{kg} \cdot \mathrm{K})$ inner diameter of test tube, $\mathrm{m}$ outer diameter of test tube, $\mathrm{m}$ external diameter of annulus, $m$ hydraulic diameter of annulus, $m$ Fanning friction factor gravitational acceleration, $\mathrm{m} / \mathrm{s}^{2}$ mass flux, $\mathrm{kg} /\left(\mathrm{m}^{2} \cdot \mathrm{s}\right)$ 
h

$h_{l v}$

I

k

L

LMTD

m

$M A D$

N

$\operatorname{Pr}$

$Q$

$q$

$\mathrm{Re}$

T

U

V

$x$

Greek symbols

$\mu$

$\theta$

$\rho$

$\varepsilon$

$\delta$

$\lambda_{\mathrm{ph}}$

Subscripts

ave

cal

dry

e

$\exp$

$i$

in

$l$

lat

$o$

out

ph

pre

ref

$s$

sat

sens

tp

ts

$v$

wall heat transfer coefficient, $\mathrm{W} /\left(\mathrm{m}^{2} \cdot \mathrm{K}\right)$

latent heat of vaporization, $\mathrm{J} / \mathrm{kg}$

electric current, $\mathrm{A}$

thermal conductivity, $\mathrm{W} /(\mathrm{m} \cdot \mathrm{K})$

tube length, $\mathrm{m}$

logarithmic mean temperature, $\mathrm{K}$

mass flow rate, $\mathrm{kg} / \mathrm{s}$

mean absolute deviation

number of points

Prandtl number

heat transfer amount, $\mathrm{W}$

heat flux, W/m²

Reynolds number

temperature, $\mathrm{K}$

relative uncertainty

electric voltage, $\mathrm{V}$

vapor quality

dynamic viscosity, $\mathrm{Pa} \cdot \mathrm{s}$

angle, ${ }^{\circ}$

density, $\mathrm{kg} / \mathrm{m}^{3}$

void fraction

liquid film thickness, $\mathrm{m}$

heat balance factor of the preheater

average

calculation

dry-out

enhanced

experimental

inner

inlet

liquid phase

latent heat

outer

outlet

preheating section

predicted

refrigerant

smooth

saturated

sensible heat

two-phase

test section

vapor phase

tube wall

\section{References}

1. Webb, R.L.; Kim, N.-H. Principles of Enhanced Heat Transfer, 2nd ed.; Taylor \& Francis: Abingdon, UK, 2005.

2. Wang, Y.; He, Y.-L.; Lei, Y.-G.; Zhang, J. Heat transfer and hydrodynamics analysis of a novel dimpled tube. Exp. Fluid Sci. 2010, 34, 1273-1281. [CrossRef]

3. Li, M.; Khan, T.S.; Al-Hajri, E.; Ayub, Z.H. Single phase heat transfer and pressure drop analysis of a dimpled enhanced tube. Appl. Eng. 2016, 101, 38-46. [CrossRef] 
4. Li, M.; Khan, T.S.; Al Hajri, E.; Ayub, Z.H. Geometric optimization for thermal-hydraulic performance of dimpled enhanced tubes for single phase flow. Appl. Eng. 2016, 103, 639-650. [CrossRef]

5. Vicente, P.G.; García, A.; Viedma, A. Heat transfer and pressure drop for low Reynolds turbulent flow in helically dimpled tubes. Int. J. Heat Mass Transf. 2002, 45, 543-553. [CrossRef]

6. Kukulka, D.J.; Smith, R. Thermal-hydraulic performance of Vipertex 1EHT enhanced heat transfer tubes. Appl. Eng. 2013, 61, 60-66. [CrossRef]

7. Lei, X.-S.; Shuang, J.-J.; Yang, P.; Liu, Y.-W. Parametric study and optimization of dimpled tubes based on Response Surface Methodology and desirability approach. Int. J. Heat Mass Tran. 2019, 142, 118453. [CrossRef]

8. Suresh, S.; Chandrasekar, M.; Chandra Sekhar, S. Experimental studies on heat transfer and friction factor characteristics of $\mathrm{CuO} /$ water nanofluid under turbulent flow in a helically dimpled tube. Exp. Fluid Sci. 2011, 35, 542-549. [CrossRef]

9. Guo, S.P.; Wu, Z.; Li, W.; Kukulka, D.; Sunden, B.; Zhou, X.P.; Wei, J.J.; Simon, T. Condensation and evaporation heat transfer characteristics in horizontal smooth, herringbone and enhanced surface EHT tubes. Int. J. Heat Mass Transf. 2015, 85, 281-291. [CrossRef]

10. Li, W.; Chen, J.; Zhu, H.; Kukulka, D.J.; Minkowycz, W.J. Experimental study on condensation and evaporation flow inside horizontal three dimensional enhanced tubes. Int. Commun. Heat Mass 2017, 80, 30-40. [CrossRef]

11. Aroonrat, K.; Wongwises, S. Experimental study on two-phase condensation heat transfer and pressure drop of R-134a flowing in a dimpled tube. Int. J. Heat Mass Transf. 2017, 106, 437-448. [CrossRef]

12. Aroonrat, K.; Wongwises, S. Experimental investigation of condensation heat transfer and pressure drop of R-134a flowing inside dimpled tubes with different dimpled depths. Int. J. Heat Mass Transf. 2019, 128, 783-793. [CrossRef]

13. Aroonrat, K.; Wongwises, S. Condensation heat transfer and pressure drop characteristics of R-134a flowing through dimpled tubes with different helical and dimpled pitches. Int. J. Heat Mass Transf. 2018, 121, 620-631. [CrossRef]

14. Sarmadian, A.; Shafaee, M.; Mashouf, H.; Mohseni, S.G. Condensation heat transfer and pressure drop characteristics of R-600a in horizontal smooth and helically dimpled tubes. Exp. Fluid Sci. 2017, 86, 54-62. [CrossRef]

15. Shafaee, M.; Mashouf, H.; Sarmadian, A.; Mohseni, S.G. Evaporation heat transfer and pressure drop characteristics of R-600a in horizontal smooth and helically dimpled tubes. Appl. Eng. 2016, 107, 28-36. [CrossRef]

16. Ayub, Z.H.; Ayub, A.H.; Ribatski, G.; Moreira, T.A.; Khan, T.S. Two-phase pressure drop and flow boiling heat transfer in an enhanced dimpled tube with a solid round rod insert. Int. J. Refrig. 2017, 75, 1-13. [CrossRef]

17. Li, W.; Chen, X.; Chen, J.-X.; Sun, Z.-C.; Simon, T.W. Shell-Side Flow Condensation of R410A on Horizontal Tubes at Low-Mass Fluxes. J. Heat Transf. 2016, 139. [CrossRef]

18. Tang, W.; Li, W. Shell-side Condensation Characteristics of R410a on Horizontal Enhanced Tubes. J. Heat Transf. 2019. [CrossRef]

19. Al-Sallami, W.; Al-Damook, A.; Thompson, H.M. A numerical investigation of the thermal-hydraulic characteristics of perforated plate fin heat sinks. Int. J. Sci. 2017, 121, 266-277. [CrossRef]

20. Dorao, C.A.; Fernandino, M. Simple and general correlation for heat transfer during flow condensation inside plain pipes. Int. J. Heat Mass Transf. 2018, 122, 290-305. [CrossRef]

21. Li, W.; Tang, W.; Chen, J.; Zhu, H.; Kukulka, D.J.; He, Y.; Sun, Z.; Du, J.; Zhang, B. Convective condensation in three enhanced tubes with different surface modifications. Exp. Fluid Sci. 2018, 97, 79-88. [CrossRef]

22. Gnielinski, V. New Equations for Heat and Mass Transfer in Turbulent Pipe and Channel Flows. NASA Sti/Recon Tech. Rep. A 1976, 75, 8-16.

23. Petukhov, B.S. Heat Transfer and Friction in Turbulent Pipe Flow with Variable Physical Properties. Adv. Heat Transf. 1970, 6, 503-564.

24. Lemmon, E.W.; Huber, M.L.; Mclinden, M.O. NIST Standard Reference Database 23: Reference Fluid Thermodynamic and Transport Properties-REFPROP, version 9.1; Standard Reference Data Program; National Institute of Standards and Technology: Gaithersburg, MD, USA, 2010.

25. Moffat, R.J. Describing the uncertainties in experimental results. Exp. Fluid Sci. 1988, 1, 3-17. [CrossRef] 
26. Chen, J.-X.; Chen, X.; He, Y.; Kukulka, D.; Li, W.; Liu, L.; Ma, L.; Smith, R.; Zhang, B. Investigation on flow condensation of refrigerant in annulus of smooth and enhanced tube-in-tube heat exchanger. Heat Mass Transf. 2019, 55, 223-234. [CrossRef]

27. Cavallini, A.; Col, D.D.; Doretti, L.; Matkovic, M.; Rossetto, L.; Zilio, C.; Censi, G. Condensation in Horizontal Smooth Tubes: A New Heat Transfer Model for Heat Exchanger Design. Heat Transf. Eng. 2006, 27, 31-38. [CrossRef]

28. Chen, J.C. Correlation for Boiling Heat Transfer to Saturated Fluids in Convective Flow. Ind. Eng. Chem. Process Des. Dev. 1966, 5, 322-329. [CrossRef]

29. Cooper, M.G. Saturation nucleate pool boiling: A simple correlation. IChemE Symp. Ser. 1984, 86, 786. [CrossRef]

30. Wojtan, L.; Ursenbacher, T.; Thome, J.R. Investigation of flow boiling in horizontal tubes: Part I-A new diabatic two-phase flow pattern map. Int. J. Heat Mass Tran. 2005, 48, 2955-2969. [CrossRef]

31. Chen, J.; Li, W. Local flow boiling heat transfer characteristics in three-dimensional enhanced tubes. Int. J. Heat Mass Transf. 2018, 121, 1021-1032. [CrossRef]

(C) 2020 by the authors. Licensee MDPI, Basel, Switzerland. This article is an open access article distributed under the terms and conditions of the Creative Commons Attribution (CC BY) license (http://creativecommons.org/licenses/by/4.0/). 